\title{
How to treat severe infections in critically ill neutropenic patients?
}

Lara Zafrani ${ }^{1}$ and Elie Azoulay ${ }^{1,2^{*}}$

\begin{abstract}
Severe infections in neutropenic patient often progress rapidly leading to life-threatening organ dysfunction requiring admission to the Intensive Care Unit. Management strategies include early adequate appropriate empirical antimicrobial, early admission to ICU to avoid any delay in the diagnostic and therapeutic management of organ dysfunction. This review discusses the main clinical situations encountered in critically ill neutropenic patients. Specific diagnostic and therapeutic approaches have been proposed for acute respiratory failure, shock, neutropenic enterocolitis, catheter-related infections, cellulitis and primary bacteriemia. Non anti-infectious agents and recent advances will also be discussed. At present, most of large-scale studies and recommendations in neutropenic patients stem from hematological patients and will need further validation in ICU patients.
\end{abstract}

\section{Review Introduction}

Neutropenia is a decrease in circulating neutrophil counts in the peripheral blood. An absolute neutrophil count of $1,000-1,500$ cells $/ \mathrm{mm}^{3}$ defines mild neutropenia, $500-1,000$ cells $/ \mathrm{mm}^{3}$ defines moderate neutropenia, and $<500$ cells $/ \mathrm{mm}^{3}$ defines severe neutropenia. Myelodysplastic syndromes and hematologic malignancies typically cause pancytopenia. A minority of cases present with isolated neutropenia. Moreover, cancer patients may experience neutropenia as a side effect of chemotherapy or radiotherapy. Over the last decades, increased treatment intensity in cancer patients has translated into better survival [1]. More patients are being treated, more intensive regimens are being used, and patients more often undergo stem cell transplantation with the primary goal to control the disease. The result, in most of the cases, is an increase in the number of cases of patients with neutropenia [2]. Infection is the major cause of morbidity and mortality in neutropenic patients [3]. The risk of serious complications depends mainly on the duration of neutropenia ( $>7$ days) and the presence of comorbidities, such as

\footnotetext{
* Correspondence: elie.azoulay@sls.aphp.fr

${ }^{1}$ AP-HP, Hôpital Saint-Louis, Medical ICU. Groupe de Recherche Respiratoire en Réanimation Onco-Hématologique (Grrr-OH), Paris, France

${ }^{2}$ Medical Intensive Care Unit, Hôpital Saint-Louis, ECSTRA team, Biostatistics and clinical epidemiology, UMR 1153 (center of epidemiology and biostatistic Sorbonne Paris Cité, CRESS), INSERM, Paris Diderot Sorbonne University, Paris, France
}

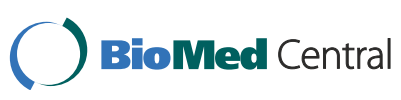

(c) 2014 Zafrani and Azoulay; licensee BioMed Central Ltd. This is an Open Access article distributed under the terms of the Creative Commons Attribution License (http://creativecommons.org/licenses/by/4.0), which permits unrestricted use, distribution, and reproduction in any medium, provided the original work is properly credited. The Creative Commons Public Domain Dedication waiver (http://creativecommons.org/publicdomain/zero/1.0/) applies to the data made available in this article, unless otherwise stated. hepatic or renal dysfunction $[4,5]$. Infections often progress rapidly leading to hypotension and/or other life-threatening complications requiring admission to the Intensive Care Unit (ICU). ICU admission may be due to inappropriate antibiotherapy. Unfortunately, even when appropriate antibiotics are administrated in a timely manner, neutropenic patients may still end up in an ICU. Indeed, the excessive inflammatory response associated with sepsis may lead to multiple organ failures. In addition, the source of infections is more difficult to identify in neutropenic patients than it is in patients with normal immune function, since symptoms of infection are often diminished. The spectrum of potential pathogens is broad and early diagnosis is essential for guiding treatment and minimizing nonessential drug therapy. In this review we will focus mainly on neutropenia secondary to hematological malignancies and chemotherapyinduced neutropenia in adults.

\section{Empirical antimicrobial therapy in ICU}

In severe infections, empirical antibiotic/antifungal therapy in suspected infections should be tailored to the individual patient to maximize the chances that the therapy is microbiologically appropriate. There is a clear link between microbiologically adequate empirical therapy and successful outcome from infections [6-8].

\section{Antibacterial drugs}

Guidelines have been developed for the management of fever in neutropenic patients with cancer, including 
hematopoietic cell transplant recipients [4,9] (Table 1). The Infectious Diseases Working Party of the German Society of Hematology and Oncology published guidelines on the diagnosis and management of sepsis in neutropenic patients where they address specifically the management of critically-ill patients [10]. Unfortunately, prospective randomized studies related to the ICU setting for neutropenic patients are lacking. Therefore, these recommendations are based on studies performed in the non-critically ill patient. The recommended empirical antibiotic therapy is the same as the antibiotic therapy recommended in US guidelines. The aim of empiric therapy is to cover the most likely and most virulent pathogens that may rapidly cause serious or life-threatening infection in neutropenic patients. In all febrile neutropenic patients, empiric broad-spectrum antibacterial therapy should be initiated immediately after blood cultures have been obtained and before any other investigations have been completed [4]. The Infectious Diseases Society of America (IDSA) recommends an empiric monotherapy with an anti-pseudomonal beta-lactam agent, such as piperacillintazobactam, cefepime, meropenem, or imipenem [4]. In critically ill patients, combination antibiotic regimens are usually used, although none has been shown to be clearly superior to others or to monotherapy $[11,12]$. However most of these data has not analyzed patients who required ICU admission. Such patients remain a subset for which standardized evidence-based recommendations are warranted [13]. Recommended combination regimens include an extended-spectrum beta-lactam combined with an aminoglycoside or a beta-lactam combined with a fluoroquinolone [12]. In the ICU setting, Legrand et al. found that combination antibiotic therapy including an aminoglycoside was associated with lower mortality in neutropenic patients with severe sepsis or septic shock
[14]. Vancomycin (or other agents that target grampositive cocci) is recommended in case of hemodynamic instability, in suspected central venous catheter (CVC)related infection, in skin or soft tissue infection or severe mucositis and in patients who are colonized with methicillin-resistant S. aureus [4,15]. Abdominal distension or diarrhea should prompt suspicion of either neutropenic enterocolitis (typhlitis) or Clostridium difficile colitis. Suspected neutropenic enterocolitis should prompt the addition of metronidazole and antifungal therapy for Candida coverage [16].

\section{Diagnosis and treatment of fungal disease}

The IDSA recommends addition of an empiric antifungal agent after four to seven days in high-risk neutropenic patients who are expected to have a total duration of neutropenia $>7$ days who have persistent or recurrent fever and in whom reassessment does not yield a cause [4]. However, in ICU patients who are clinically unstable, antifungal therapy should be considered earlier, though no data are available in this specific setting.

The choice of agent for empiric antifungal therapy depends upon which fungi are most likely to be causing infection, as well as the toxicity profiles and cost [4]. In patients who have never been exposed to antifungal agents, Candida spp are the most likely cause of invasive fungal infection. In patients receiving fluconazole prophylaxis, fluconazole-resistant Candida spp (eg, C. glabrata and C. krusei) and invasive mold infections, particularly Aspergillus spp, are the most likely causes [4]. The 2009 North American recommendations propose empirical broad-spectrum treatment with an echinocandin for all ICU patients irrespective of previous exposition to azole agents [17]. This is in accordance with Leroy and al's study, conducted in neutropenic and non neutropenic

Table 1 Empiric antibiotic therapy in high risk patients with neutropenic fever (adapted from the IDSA guidelines [4])

\begin{tabular}{|c|c|c|}
\hline Antibiotherapy & Indications & Grade of recommendation \\
\hline Antipseudomonal $\beta$-lactam agent & All high risk patients with neutropenic fever & $A-I$ \\
\hline \multicolumn{3}{|c|}{ - Carbapenem (meropenem or imipenem-cilastatin) } \\
\hline \multicolumn{3}{|l|}{ Piperacillin-tazobactam } \\
\hline Aminoglycosides & Hemodynamic instability & B-III \\
\hline \multirow[t]{3}{*}{ Vancomycin } & - Suspected catheter-related infections & $A-I$ \\
\hline & - Skin or soft-tissue infection & \\
\hline & - Hemodynamic instability & \\
\hline Vancomycin, linezolid or daptomycin & Risk of methicillin-resistant Staphylococcus aureus & B-III \\
\hline Linezolid or daptomycin & Risk of vancomycine-resistant enterococcus & B-III \\
\hline Carbapenem & $\begin{array}{l}\text { Risk of extended-spectrum } \beta \text {-lactamase-producing } \\
\text { gram negative bacteria }\end{array}$ & $B-111$ \\
\hline Polymyxin-colistin or tigecycline & Risk of Klebsiella pneumonia carbapenemase (KPC) & C-III \\
\hline - Ciprofloxacin + clindamycin & Penicillin-allergic patients & $A-\|$ \\
\hline - Aztreonam + vancomycin & & \\
\hline
\end{tabular}


ICU patients, that showed a high incidence (38\%) of fluconazole resistant Candida, especially in neutropenic patients [18]. Voriconazole or a lipid formulation of amphotericin B are preferred in patients with pulmonary findings suggestive of an invasive mold infection due to higher failure rates with caspofungin in treating invasive aspergillosis, which is the most common cause of mold infections [19]. Of note, large-scale clinical studies on antifungal therapy in immunocompromised patients usually exclude patients with baseline characteristics that are commonly seen in ICU patients, including patients with liver function abnormalities or renal failure or patients requiring vasopressors or mechanical ventilation. In a retrospective study of hematology patients with invasive pulmonary aspergillosis requiring mechanical ventilation in ICU, Burghi et al. found that voriconazole therapy was independently associated with lower mortality [20].

Amphotericin B should be preferred if mucormycosis is suspected, since voriconazole is inactive against mucormycosis [21]. Moroever, in septic patients who have already received an azole antifungal agent, Amphotericin B should be also the drug of choice for empirical therapy.

In addition to gold-standard methods such as blood cultures, histopathology and cultures of fluids or deep tissues, non-culture diagnostic tests may be useful to diagnose promptly fungal disease. Numerous methods have been developed for detecting fungal cell antigens such as Aspergillus galactomannan (GM), 1,3- $\beta$-D-glucan or nuclear amplification assays to identify fungal DNA for early noninvasive detection of filamentous fungi in febrile neutropenic patients. A positive (i.e. $>0.5$ OD) GM test from blood has been accepted as a significant finding indicating a probable invasive fungal infection in severely immunocompromised patients [22]. The 1,3- $\beta$-D-glucan assay can be a useful adjunct to blood cultures and biopsy to diagnose invasive candidiasis [23-25]. Some authors suggest that a combination of blood cultures with the $\beta$-D-glucan assay or the polymerase chain reaction (PCR) increases the sensitivity of diagnostic testing compared to blood cultures alone [26]. Detection of candida DNA by PCR is more sensitive and provides earlier results for the diagnosis of invasive candidiasis [27]. However, PCR is not yet standardized and so far the value of PCR as early marker of invasive candidiasis remains unclear.

Hepatic or renal dysfunctions should be taken into consideration when choosing an antifungal drug. For example, amphotericin B deoxycholate will be avoided in case of acute kidney injury and voriconazole will be avoided in case of liver dysfunction. In addition, many aspects of antifungal therapy that are relevant to the ICU population have not been sufficiently addressed in clinical studies, including the pharmacokinetic profile of antifungals in patients with underlying renal or hepatic dysfunction; the dose-response relationship; the best route of administration (oral, enteral, or parenteral); especially, drug interactions with frequently used "ICU drugs".

\section{Treatment duration and de-escalation of antimicrobial treatment}

Guidelines suggest continuing antimicrobial treatment until neutropenia recovery [4]. A recent work by Mokart, $\mathrm{D}$ and al. studied de-escalation of antimicrobial treatment in neutropenic patients with severe sepsis [28]. Sixty-eight percent of patients in this serie underwent de-escalation during neutropenia. Authors did not find a deleterious impact of de-escalation on the survival. Of importance, in the de-escalated patients, treatment was never interrupted before neutropenia recovery. Studies about de-escalation are warranted in patients with neutropenia. Indeed, now that it seems feasible, large interventional trials are needed to understand if survival benefits can be expected in these patients $[29,30]$.

\section{Clinical presentations and specific management in ICU}

Figure 1 summarizes the management of severe infections in neutropenic patients according to their clinical presentation at ICU admission.

\section{Neutropenia and acute respiratory failure}

Acute respiratory failure (ARF) occurs up to $50 \%$ of patients with neutropenia [31]. These patients should be admitted early in ICU in order to benefit from early noninvasive diagnostic and therapeutic management. Indeed, the prognosis is worsened when ICU admission is delayed [32]. We described previously the most important criteria to consider when evaluating these patients, using the mnemonic DIRECT [31,33]: Delay since the onset of malignancy or haematopoietic stemcell transplantation (HSCT), since symptom onset and since the implementation of antibiotics/prophylaxis; pattern of Immune deficiency; Radiographic appearance; Experience and knowledge of the literature; Clinical picture; and findings by high-resolution computed Tomography $(C T)$ of the chest $[31,33]$. The DIRECT method may help physicians to determine the most likely causes of ARF in a cancer patient and guide further investigations and/or empirical therapy.

Fiberoptic bronchoscopy and bronchoalveolar lavage is safe when performed early after ICU admission. However, this procedure adds diagnostic information to that obtained by noninvasive tests in only $18 \%$ of patients and had little therapeutic impact. Noninvasive tests identify the cause of acute respiratory failure more frequently and more quickly than does the bronchoalveolar lavage [34]. Conventional chest radiographs show abnormalities 


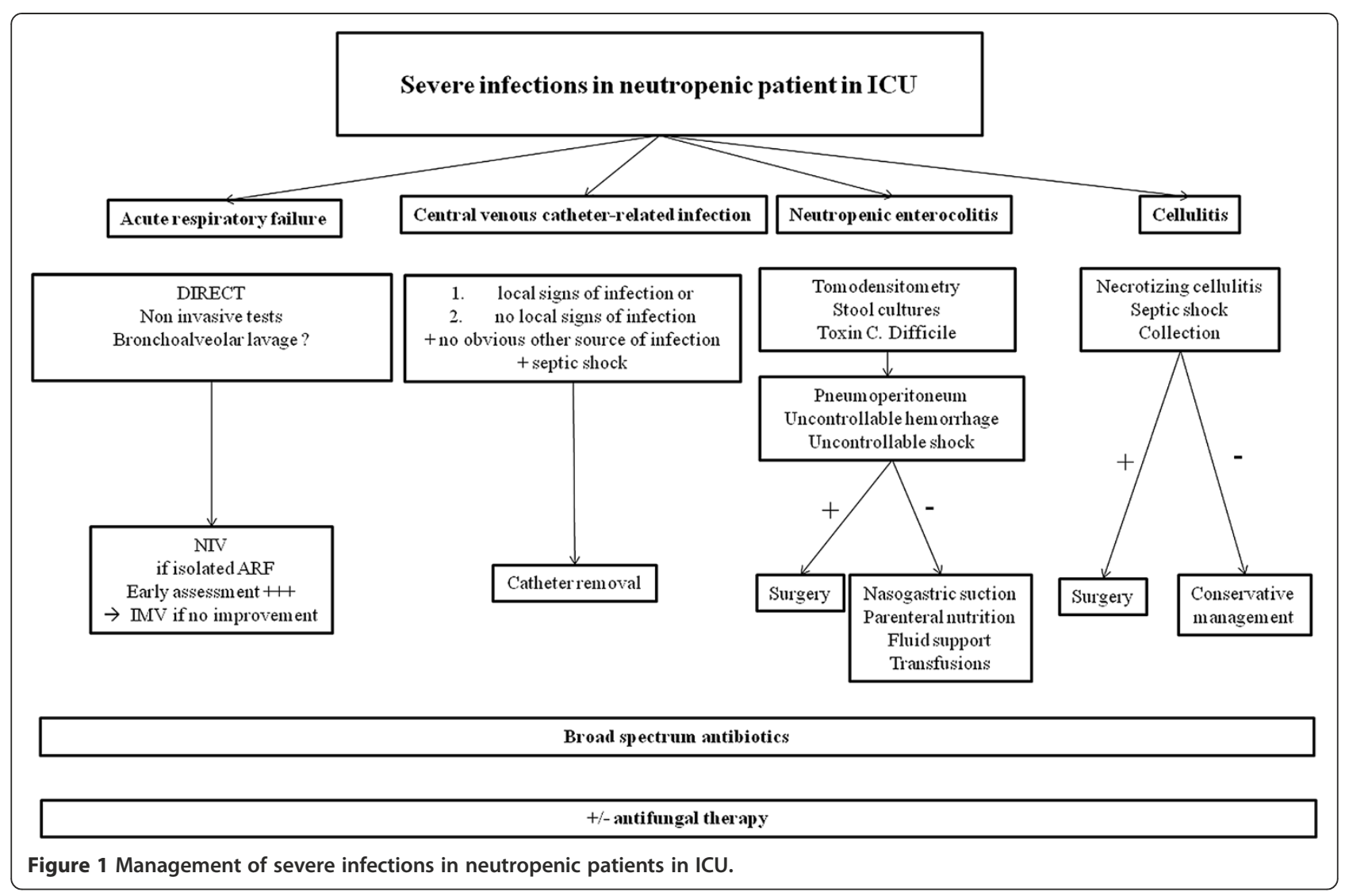

in $<2 \%$ of febrile neutropenic patients without clinical findings indicating lower respiratory tract infection $[35,36]$. In patients persistently febrile after $>48 \mathrm{~h}$ of broad-spectrum antibacterial therapy, $10 \%$ of chest radiographs are abnormal, whereas highresolution CT scans at this time reveal pathological findings in 50\% of patients [37].

Beyond early identification of lung infiltrates, CT findings may allow for distinguishing fungal from nonfungal lung infiltrates $[38,39]$. Nodular or cavitary lesions are suggestive of invasive filamentous fungal infection; however, differential diagnoses include pneumonia due to other microorganisms including mycobacteria, Nocardia, Pneumocystis or Pseudomonas aeruginosa as well as lung involvement by underlying malignancies, so that comparison to previous CT scans in an individual patient is essential $[22,23,40,41]$.

An initial broad-spectrum treatment with combinations of a $\beta$-lactam or carbapenem plus an aminoglycoside or antipseudomonal fluoroquinolone is recommended during pneumonia in neutropenic patients $[4,42]$. Beside antimicrobial drugs, the question of non-invasive mechanical ventilation (NIV) as opposed to invasive mechanical ventilation in these patients is crucial. Studies evaluating NIV in hematology patients highlight the deleterious effects of
NIV failure and late intubation [43-45]. Curative NIV should be discouraged in patients with an associated extra-respiratory organ failure, and in those with mild to severe ARDS. We recommend a cautious use of curative NIV only in patients with isolated ARF and with an early assessment of its efficacy. When no improvement is seen, invasive mechanical ventilation must be considered early to ensure the highest chance of survival for neutropenic patients with hypoxemic ARF. Readers must bear in mind that trials that evaluated NIV at a time where mechanical ventilation was associated with $80-90 \%$ mortality are not relevant anymore.

\section{Acute respiratory distress syndrome (ARDS) and neutropenia recovery}

Acute respiratory failure that occurs 3 until days before to 3 days after neutropenia recovery may be associated with a deterioration in oxygenation and exacerbation of pre-existing pulmonary disease [46,47]. Patients at risk for ARDS during neutropenia recovery are those with pulmonary infiltrates during neutropenia [46]. Other risk factors that have been suggested include delayed or prolonged neutropenia [46], and pneumonia [48]. G-CSF should be avoided in this context (cf infra). 


\section{Catheter removal}

Deciding when to remove CVC is a common problem in neutropenic patients in ICU. In patients with bacteremia due to Enterobacteriaceae, enterococci or Pseudomonas, with no local signs of catheter infection or septic shock, microbial growth in peripheral blood before 2 hours after growth in a sample obtained simultaneously from the catheter often indicates bacterial translocation from the intestine [49]. CVC should be considered for removal in patients with septic shock, without an obvious other source of infection as the absence of local signs and symptoms are notoriously insensitive in the neutropenic host. In a cohort study of neutropenic cancer patients admitted to the ICU for severe sepsis or septic shock, Legrand et al. found that routinely removing indwelling catheters early on in patients with no other detectable focus on infection was independently associated with survival [14]. If needed, a new catheter may be placed in a different site.

\section{Neutropenic enterocolitis (typhlitis)}

The intestinal tract is a common site of infection in neutropenic patients. Neutropenic enterocolitis, also known as typhlitis is a life-threatening condition due to inflammatory/hemorrhagic/necrotizing involvement of the lower intestinal tract [50]. Criteria for neutropenic enterocolitis associate presence of fever, abdominal pain and demonstration of the bowel wall thickening of more than $4 \mathrm{~mm}$ (transversal scan) over more than $30 \mathrm{~mm}$ (longitudinal scan) in any segment by ultrasonography or computed tomography [16]. Moreover, other diagnoses such as $C$. difficile associated colitis, graft-versus host disease, or other abdominal syndromes including cholecystitis, cholangitis, appendicitis need to be ruled out. The management of neutropenic enterocolitis has evolved over the years as clinical experience has grown. Recent studies have reported the success of conservative treatment in most patients. Surgical intervention is now reserved for selected cases of neutropenic enterocolitis based on (1) the persistence of gastrointestinal bleeding despite correction of coagulopathies and thrombocytopenia (2) free air in the intraperitoneal cavity indicative of bowel perforation and (3) clinical deterioration despite optimal medical management. The presence of gaz in the mucous lining of the small or large intestine is indicative of pneumatosis intestinalis. This situation refers to a necrotizing enterocolitis and can be considered as an indication for urgent surgery.

Conservative management is recommended initially when these criteria are absent [50]. Badgwell et al. suggested better outcomes if it was possible to delay surgery until recovery from neutropenia [51]. General supportive measures include bowel rest with nasogastric suction, parenteral nutrition if necessary, and intravenous fluid support. Platelet transfusions may be necessary in patients with severe thrombocytopenia. In our hospital, because of close monitoring needed in these patients, early ICU admission is the rule.

\section{Perianal cellulitis}

Perianal cellulitis should be promptly recognized in neutropenic patients, as they are associated with significant morbidity and mortality [52]. Necrotizing cellulitis and cellulitis-induced septic shock require surgery. However, surgery is sometimes a complex decision and some authors suggest that, in the absence of septic shock, the management depends on the presence of fluctuation or collection [52]. In Morcos et al. serie, patients without collection or fluctuation were treated conservatively with antibiotics [52]. However, patients who are managed conservatively, should be monitored closely by both intensivist and surgeons until they improve. Indeed, sometimes fluctuation/collection or septic shock become evident in the later course.

\section{Vasopressor regimen during septic shock}

International guidelines for management of severe sepsis and septic shock apply for neutropenic patients [13]. Guidelines from the infectious diseases working party of the German Society of Hematology and Oncology [10] for the management of sepsis in neutropenic patient recommend the use of norepinephrine as the drug of choice if a sufficient mean arterial pressure (> $65 \mathrm{mmHg}$ ) cannot be achieved by fluid resuscitation, associated with dobutamine in case of sepsis-related myocardial depression . Moreover, D. Schnell and al. studied the impact of a recent chemotherapy on the duration and intensity of the norepinephrine support during septic shock [53]. Cancer patients recently treated with chemotherapy had similar needs in vasopressor support during septic shock compared with untreated cancer patients and patients without malignancy [53].

\section{Non anti-infectious agents G-CSF and GM-CSF}

Haemopoietic growth factors, such as granulocyte colonystimulating factor (G-CSF) and granulocyte-macrophage colony-stimulating factor (GM-CSF) have been assessed in several clinical trials $[54,55]$. The known effect of G-CSF and GM-CSF in increasing the number of circulating neutrophil granulocytes was the rationale for clinical studies assessing their role as additional therapy to antibiotics in febrile patients with chemotherapy-induced neutropenia. A meta-analysis of 13 randomized controlled trials showed that G-CSF reduces the time to neutrophil recovery and the length of hospitalization [55]. However, overall mortality appeared not to be influenced. In ICU, in a retrospective study of 28 neutropenic patients who received G-CSF compared to 33 patients who did not 
received G-CSF, Gruson et al. did not found any difference in terms of clinical outcome and occurrence of nosocomial infections [56]. Moreover, as mentioned above, in patients with pulmonary infiltrates during neutropenia, G-CSF-induced neutropenia recovery carries a risk of respiratory status deterioration with ARDS [57].

\section{Granulocyte transfusion}

Granulocyte transfusions have been most frequently employed in the management of patients with neutropenic sepsis that is unresponsive to conventional antimicrobial therapy. However, therapeutic administration of granulocyte transfusions in the neutropenic host with severe infection has no proven benefit. A cochrane database systematic review concludes that there is inconclusive evidence to support or refute the use of granulocyte transfusions [58]. More recently, in 30 severely ill neutropenic patients with haematological malignancies, Cherif et al. demonstrated a good feasibility of granulocyte transfusions and signs of clinical efficacy [59]. Specific data in ICU setting are not currently available. Moreover, complications of granulocyte transfusions have been reported such as fatal CMV infection, allo-immunization and transfusion-related acute lung injury (TRALI) syndrome. Therefore, granulocyte transfusions are not recommended in routine use and should be avoided in ICU.

\section{Intravenous immunoglobulin}

Polyclonal intravenous immunoglobulins have been suggested to be beneficial during sepsis by modulating the immune response and neutralizing bacterial endo and exotoxins and stimulating serum bactericidal activity. In neutropenic patients with hematological malignancies and severe sepsis or septic shock, the prospective randomized controlled study conducted by Hentrich et al. found no beneficial effect of intravenous IgMA-enriched immunoglobulin therapy [60].

\section{Emerging trends and recent advances Multidrug resistant bacteria}

Multidrug-resistant bacteria have become more prevalent among neutropenic patients because of their greater time exposure to the health-care environment and selective pressure from prophylactic and therapeutic antimicrobial drugs. In neutropenic patient, among Gram-negative bacteria, Pseudomonas aeruginosa, Acinetobacter species, Escherichia coli, Klebsielle pneumonia and Stenotrophomonas maltophilia are increasingly found to exhibit multidrug resistance $[61,62]$. Antibiotic selection pressure promotes the induction of extended-spectrum chromosomal $\beta$-lactamases (ESBL) after the use of $\beta$-lactams $[63,64]$ and the selection of enterobacteria with decreased porin production after the use of carbapenems [62]. Enterobacteriaceae that produce Klebsiella pneumonia carbapenemases (KPCs) that confer resistance to all $\beta$ lactams, are now reported worldwide and may require treatment with colistin or tigecycline [65,66]. Fluoroquinolone exposure is associated with the emergence of methicillin-resistant Staphylococcus aureus (MRSA) and penicillin-resistant streptococci [67]. Vancomycine resistant enterococci (VRE) has become a prominent pathogen in cancer patients. Linezolid and daptomycin have been approved for use in infections with VRE (including those with associated bacteremia) with linezolid often used as a first-line treatment. Early reports of linezolid resistant enterococci occurred predominantly in immunocompromised hosts who resided in an ICU [68].

\section{New antifungal drugs}

- To date, posaconazole is only available in oral suspension. A study evaluating the pharmacokinetics and adverse effects of an intravenous formulation of posaconazole is currently being completed (ClinicalTrials.gov. Pharmacokinetics, safety, and tolerability of intravenous posaconazole solution followed by oral posaconazole suspension in subjects at high risk for invasive fungal infections (NCT01075984). Available from: ClinicalTrials.gov). An intravenous formulation of posaconazole would be of particular interest in ICU patients.

- New antifungal drugs are currently being investigated. However, to date, published data are very scarce. New azole antifungals include Ravuconazole, Isavuconazole and Albaconazole. The spectrum of activity of these 3 drugs, based on in vitro studies, include Candida spp. (including fluconazole-resistant isolates), Aspergillus spp and Cryptococcus neoformans [69,70]. Ongoing clinical trials involve the treatment of invasive aspergillosis and candidiasis. However, published results are to date unavailable. (Ravuconazole in preventing fungal infections in patients undergoing allogeneic stem cell transplantation 2013; available from http://www.clinicaltrials.gov). Furthermore, to the best of our knowledge, there are no specific study ongoing in the ICU setting. There are also case reports with a combination of a new monoclonal antibody against Candida spp (including fluconazoleresistant species), Efungumab, with other antifungals in invasive candidiasis [71,72]. However, no large scale studies are published at this time.

\section{Combination antifungal therapy}

Data supporting the routine use of antifungal combinations for invasive candidiasis are limited and controversial [73]. Amphotericin B plus flucytosine is standard therapy for central nervous system (CNS) candidiasis, Candida endophthalmitis and Candida endocarditis. However, clinical data supporting such recommendations are generally lacking [17]. In invasive aspergillosis, the combination of two agents (voriconazole plus echinocandin) is currently 
recommended only in salvage therapy for pulmonary aspergillosis. However, an unpublished trial has proven no benefit of combination of antifungal therapy. The combination of caspofungin plus voriconazole is also a treatment option for CNS aspergillosis despite the limited CNS penetration of the echinocandin [74].

\section{Conclusion}

Infections in neutropenic patients often progress rapidly and require prompt admission in ICU. Early adequate management, as a part of a collegial medical procedure involving intensivists, hematologists and/or oncologists, includes prompt initiation of antimicrobial therapy and life sustaining therapies. Multidrug-resistant bacteria, particularly from the nosocomial setting, have become more prevalent among neutropenic patients in ICU over the last decades because of their greater time exposure to the health-care environment and selective pressure from prophylactic and therapeutic anti-infective exposure. The development of antimicrobial stewardship program is therefore of utmost importance. To date, benefit of non anti-infectious agents such as G-CSF or intravenous immunoglobulins has not been proven in terms of clinical outcomes. Most of large-scale studies and recommendations in neutropenic patients stem from hematological patients and have to be validated in the ICU setting.

\section{Competing interests}

The authors declare that they have no competing interests.

\section{Authors' contributions}

$L Z$ and EA carried out a review of the literature and wrote the manuscript. Both authors read and approved the final manuscript.

Received: 8 April 2014 Accepted: 9 September 2014

Published: 28 November 2014

\section{References}

1. Brenner $\mathrm{H}$, Gondos $\mathrm{A}$, Arndt $\mathrm{V}$ : Recent major progress in long-term cancer patient survival disclosed by modeled period analysis. I Clin Oncol 2007, 25(22):3274-3280

2. Azoulay E: Pulmonary infiltrates in patients with malignancies: why and how neutropenia influences clinical reasoning. Eur Respir J 2009, 33(1):6-8.

3. Viscoli C, Varnier O, Machetti M: Infections in patients with febrile neutropenia: epidemiology, microbiology, and risk stratification. Clin Infect Dis 2005, 40(Suppl 4):S240-245.

4. Freifeld AG, Bow EJ, Sepkowitz KA, Boeckh MJ, Ito Jl, Mullen CA, Raad II, Rolston KV, Young JA, Wingard JR, Infectious Diseases Society of America: Clinical practice guideline for the use of antimicrobial agents in neutropenic patients with cancer: 2010 update by the infectious diseases society of america. Clin Infect Dis 2011, 52(4):e56-93.

5. Flowers CR, Seidenfeld J, Bow EJ, Karten C, Gleason C, Hawley DK, Kuderer NM, Langston AA, Marr KA, Rolston KV, Ramsey SD: Antimicrobial prophylaxis and outpatient management of fever and neutropenia in adults treated for malignancy: American Society of Clinical Oncology clinical practice guideline. J Clin Oncol 2013, 31(6):794-810.

6. Labelle AJ, Micek ST, Roubinian N, Kollef MH: Treatment-related risk factors for hospital mortality in Candida bloodstream infections. Crit Care Med 2008, 36(11):2967-2972.

7. Ibrahim EH, Sherman G, Ward S, Fraser VJ, Kollef MH: The influence of inadequate antimicrobial treatment of bloodstream infections on patient outcomes in the ICU setting. Chest 2000, 118(1):146-155.
8. Kang Cl, Kim SH, Kim HB, Park SW, Choe YJ, Oh MD, Kim EC, Choe KW: Pseudomonas aeruginosa bacteremia: risk factors for mortality and influence of delayed receipt of effective antimicrobial therapy on clinical outcome. Clin Infect Dis 2003, 37(6):745-751.

9. Freifeld AG, Bow EJ, Sepkowitz KA, Boeckh MJ, Ito Jl, Mullen CA, Raad II, Rolston KV, Young JA, Wingard JR, Infectious Diseases Society of America: Clinical practice guideline for the use of antimicrobial agents in neutropenic patients with cancer: 2010 Update by the Infectious Diseases Society of America. Clin Infect Dis 2011, 52(4):427-431.

10. Penack O, Buchheidt D, Christopeit M, von Lilienfeld-Toal M, Massenkeil G, Hentrich M, Salwender H, Wolf HH, Ostermann H: Management of sepsis in neutropenic patients: guidelines from the infectious diseases working party of the German Society of Hematology and Oncology. Ann Oncol 2011, 22(5):1019-1029.

11. Peacock JE, Herrington DA, Wade JC, Lazarus HM, Reed MD, Sinclair JW, Haverstock DC, Kowalsky SF, Hurd DD, Cushing DA, Harman CP, Donowitz GR: Ciprofloxacin plus piperacillin compared with tobramycin plus piperacillin as empirical therapy in febrile neutropenic patients. A randomized, double-blind trial. Ann Intern Med 2002, 137(2):77-87.

12. Bliziotis IA, Michalopoulos A, Kasiakou SK, Samonis G, Christodoulou C, Chrysanthopoulou S, Falagas ME: Ciprofloxacin vs an aminoglycoside in combination with a beta-lactam for the treatment of febrile neutropenia: a meta-analysis of randomized controlled trials. Mayo Clin Proc 2005, 80(9):1146-1156.

13. Dellinger RP, Levy MM, Rhodes A, Annane D, Gerlach H, Opal SM, Sevransky JE, Sprung CL, Douglas IS, Jaeschke R, Osborn TM, Nunnally ME, Townsend SR, Reinhart K, Kleinpell RM, Angus DC, Deutschman CS, Machado FR, Rubenfeld GD, Webb S, Beale RJ, Vincent JL, Moreno R: Surviving Sepsis Campaign: international guidelines for management of severe sepsis and septic shock, 2012. Intensive Care Med 2013, 39(2):165-228.

14. Legrand M, Max A, Peigne V, Mariotte E, Canet E, Debrumetz A, Lemiale V, Seguin A, Darmon M, Schlemmer B, Azoulay E: Survival in neutropenic patients with severe sepsis or septic shock. Crit Care Med 2012, 40(1):43-49.

15. Xu XJ, Tang YM, Liao C, Song H, Yang SL, Xu WQ, Shi SW, Zhao N: Inflammatory cytokine measurement quickly discriminates gram-negative from gram-positive bacteremia in pediatric hematology/oncology patients with septic shock. Intensive Care Med 2013, 39(2):319-326.

16. Gorschluter M, Mey U, Strehl J, Ziske C, Schepke M, Schmidt-Wolf IG, Sauerbruch T, Glasmacher A: Neutropenic enterocolitis in adults: systematic analysis of evidence quality. Eur J Haematol 2005, 75(1):1-13.

17. Pappas PG, Kauffman CA, Andes D, Benjamin DK Jr, Calandra TF, Edwards JE Jr, Filler SG, Fisher JF, Kullberg BJ, Ostrosky-Zeichner L, Reboli AC, Rex JH, Walsh TJ, Sobel JD: Clinical practice guidelines for the management of candidiasis: 2009 update by the Infectious Diseases Society of America. Clin Infect Dis 2009, 48(5):503-535.

18. Leroy O, Mira JP, Montravers P, Gangneux JP, Lortholary O: Comparison of albicans vs. non-albicans candidemia in French intensive care units. Crit Care 2010, 14(3):R98.

19. Madureira A, Bergeron A, Lacroix C, Robin M, Rocha V, de Latour RP, Ferry C, Devergie A, Lapalu J, Gluckmana E, Socie G, Ghannoum M, Ribaud P. Breakthrough invasive aspergillosis in allogeneic haematopoietic stem cell transplant recipients treated with caspofungin. Int J Antimicrob Agents 2007, 30(6):551-554.

20. Burghi G, Lemiale V, Seguin A, Lambert J, Lacroix C, Canet E, Moreau AS, Ribaud P, Schnell D, Mariotte E, Schlemmer B, Azoulay E: Outcomes of mechanically ventilated hematology patients with invasive pulmonary aspergillosis. Intensive Care Med 2011, 37(10):1605-1612.

21. Sun HY, Singh N: Mucormycosis: its contemporary face and management strategies. Lancet Infect Dis 2011, 11(4):301-311.

22. Becker MJ, Lugtenburg EJ, Cornelissen JJ, Van Der Schee C, Hoogsteden HC, De Marie S: Galactomannan detection in computerized tomography-based broncho-alveolar lavage fluid and serum in haematological patients at risk for invasive pulmonary aspergillosis. Br J Haematol 2003, 121(3):448-457.

23. Ostrosky-Zeichner L, Alexander BD, Kett DH, Vazquez J, Pappas PG, Saeki F, Ketchum PA, Wingard J, Schiff R, Tamura H, Finkelman MA, Rex JH: Multicenter clinical evaluation of the $(1->3)$ beta-D-glucan assay as an aid to diagnosis of fungal infections in humans. Clin Infect Dis 2005, 41(5):654-659.

24. Bassetti M, Marchetti M, Chakrabarti A, Colizza S, Garnacho-Montero J, Kett DH, Munoz P, Cristini F, Andoniadou A, Viale P, Rocca GD, Roilides E, Sganga G, Walsh TJ, Tascini C, Tumbarello M, Menichetti F, Righi E, Eckmann C, 
Viscoli C, Shorr AF, Leroy O, Petrikos G, De Rosa FG: A research agenda on the management of intra-abdominal candidiasis: results from a consensus of multinational experts. Intensive Care Med 2013, 39(12):2092-2106.

25. Mikulska M, Calandra T, Sanguinetti M, Poulain D, Viscoli C: The use of mannan antigen and anti-mannan antibodies in the diagnosis of invasive candidiasis: recommendations from the Third European Conference on Infections in Leukemia. Crit Care 2010, 14(6):R222.

26. Nguyen MH, Wissel MC, Shields RK, Salomoni MA, Hao B, Press EG, Shields RM, Cheng S, Mitsani D, Vadnerkar A, Silveira FP, Kleiboeker SB, Clancy CJ: Performance of Candida real-time polymerase chain reaction, beta-D-glucan assay, and blood cultures in the diagnosis of invasive candidiasis. Clin Infect Dis 2012, 54(9):1240-1248.

27. McMullan R, Metwally L, Coyle PV, Hedderwick S, McCloskey B, O'Neill HJ, Patterson CC, Thompson G, Webb CH, Hay RJ: A prospective clinical trial of a real-time polymerase chain reaction assay for the diagnosis of candidemia in nonneutropenic, critically ill adults. Clin Infect Dis 2008, 46(6):890-896.

28. Mokart D, Slehofer G, Lambert J, Sannini A, Chow-Chine L, Brun JP, Berger P, Duran S, Faucher M, Blache JL, Saillard C, Vey N, Leone M: De-escalation of antimicrobial treatment in neutropenic patients with severe sepsis: results from an observational study. Intensive Care Med 2014, 40(1):41-49.

29. Bassetti M, Paiva JA, Masterton RG: The case for de-escalation in antimicrobial therapy: time to change our strategy in the management of septic shock? Intensive Care Med 2014, 40(2):284-285.

30. Garnacho-Montero J, Gutierrez-Pizarraya A, Escoresca-Ortega A, Corcia-Palomo Y, Fernandez-Delgado E, Herrera-Melero I, Ortiz-Leyba C, Marquez-Vacaro JA: De-escalation of empirical therapy is associated with lower mortality in patients with severe sepsis and septic shock. Intensive Care Med 2014, 40(1):32-40.

31. Azoulay E, Schlemmer B: Diagnostic strategy in cancer patients with acute respiratory failure. Intensive Care Med 2006, 32(6):808-822.

32. Mokart D, Lambert J, Schnell D, Fouche L, Rabbat A, Kouatchet A, Lemiale V, Vincent F, Lengline E, Bruneel F, Pene F, Chevret S, Azoulay E: Delayed intensive care unit admission is associated with increased mortality in patients with cancer with acute respiratory failure. Leuk Lymphoma 2013, 54(8):1724-1729.

33. Schnell D, Mayaux J, Lambert J, Roux A, Moreau AS, Zafrani L, Canet E, Lemiale V, Darmon M, Azoulay E: Clinical assessment for identifying causes of acute respiratory failure in cancer patients. Eur Respir J 2013 42(2):435-443

34. Azoulay E, Mokart D, Lambert J, Lemiale V, Rabbat A, Kouatchet A, Vincent F, Gruson D, Bruneel F, Epinette-Branche G, Lafabrie A, Hamidfar-Roy R. Cracco C, Renard B, Tonnelier JM, Blot F, Chevret S, Schlemmer B: Diagnostic strategy for hematology and oncology patients with acute respiratory failure: randomized controlled trial. Am J Respir Crit Care Med 2010, 182(8):1038-1046.

35. Navigante AH, Cerchietti LC, Costantini P, Salgado H, Castro MA, Lutteral MA, Cabalar ME: Conventional chest radiography in the initial assessment of adult cancer patients with fever and neutropenia. Cancer Control 2002, 9(4):346-351.

36. Oude Nijhuis CS, Gietema JA, Vellenga E, Daenen SM, De Bont ES, Kamps WA, Groen HJ, van der Jagt EJ, van der Graaf WT: Routine radiography does not have a role in the diagnostic evaluation of ambulatory adult febrile neutropenic cancer patients. Eur I Cancer 2003, 39(17):2495-2498

37. Heussel CP, Kauczor HU, Heussel GE, Fischer B, Begrich M, Mildenberger $P$, Thelen M: Pneumonia in febrile neutropenic patients and in bone marrow and blood stem-cell transplant recipients: use of high-resolution computed tomography. J Clin Oncol 1999, 17(3):796-805

38. Caillot D, Latrabe V, Thiebaut A, Herbrecht R, De Botton S, Pigneux A, Monchecourt F, Mahi L, Alfandari S, Couaillier JF: Computer tomography in pulmonary invasive aspergillosis in hematological patients with neutropenia: an useful tool for diagnosis and assessment of outcome in clinical trials. Eur J Radiol 2010, 74(3):e172-175.

39. Heussel CP, Kauczor HU, Ullmann AJ: Pneumonia in neutropenic patients. Eur Radiol 2004, 14(2):256-271.

40. Georgiadou SP, Kontoyiannis DP: Concurrent lung infections in patients with hematological malignancies and invasive pulmonary aspergillosis: how firm is the Aspergillus diagnosis? J Infect 2012, 65(3):262-268.

41. Shorr AF, Susla GM, O'Grady NP: Pulmonary infiltrates in the non-HIV-infected immunocompromised patient: etiologies, diagnostic strategies, and outcomes. Chest 2004, 125(1):260-271.
42. Maschmeyer G, Braveny I: Review of the incidence and prognosis of Pseudomonas aeruginosa infections in cancer patients in the 1990s. Eur J Clin Microbiol Infect Dis 2000, 19(12):915-925.

43. Molina R, Bernal T, Borges M, Zaragoza R, Bonastre J, Granada RM, Rodriguez-Borregan JC, Nunez K, Seijas I, Ayestaran I, Albaiceta GM: Ventilatory support in critically ill hematology patients with respiratory failure. Crit Care 2012, 16(4):R133.

44. Adda M, Coquet I, Darmon M, Thiery G, Schlemmer B, Azoulay E: Predictors of noninvasive ventilation failure in patients with hematologic malignancy and acute respiratory failure. Crit Care Med 2008, 36(10):2766-2772.

45. Azoulay E, Lemiale V: Non-invasive mechanical ventilation in hematology patients with hypoxemic acute respiratory failure: a false belief? Bone Marrow Transplant 2012, 47(4):469-472.

46. Azoulay E, Darmon M, Delclaux C, Fieux F, Bornstain C, Moreau D, Attalah H, Le Gall JR, Schlemmer B: Deterioration of previous acute lung injury during neutropenia recovery. Crit Care Med 2002, 30(4):781-786.

47. Azoulay E, Darmon M: Acute respiratory distress syndrome during neutropenia recovery. Crit Care 2010, 14(1):114.

48. Rhee CK, Kang JY, Kim YH, Kim JW, Yoon HK, Kim SC, Kwon SS, Kim YK, Kim KH, Moon HS, Park SH, Kim HJ, Lee S, Song JS: Risk factors for acute respiratory distress syndrome during neutropenia recovery in patients with hematologic malignancies. Crit Care 2009, 13(6):R173.

49. Raad I, Hanna H, Maki D: Intravascular catheter-related infections: advances in diagnosis, prevention, and management. Lancet Infect Dis 2007, 7(10):645-657.

50. Nesher L, Rolston KV: Neutropenic enterocolitis, a growing concern in the era of widespread use of aggressive chemotherapy. Clin Infect Dis 2013, 56(5):711-717.

51. Badgwell BD, Cormier JN, Wray CJ, Borthakur G, Qiao W, Rolston KV, Pollock RE: Challenges in surgical management of abdominal pain in the neutropenic cancer patient. Ann Surg 2008, 248(1):104-109.

52. Morcos B, Amarin R, Abu Sba A, Al-Ramahi R, Abu Alrub Z, Salhab M: Contemporary management of perianal conditions in febrile neutropenic patients. Eur J Surg Oncol 2013, 39(4):404-407.

53. Schnell $D$, Besset $S$, Lengline E, Maziers N, Zafrani L, Reuter D, Moreau AS, Canet E, Lemiale V, Azoulay E: Impact of a recent chemotherapy on the duration and intensity of the norepinephrine support during septic shock. Shock 2013, 39(2):138-143.

54. Lehrnbecher T, Welte $K$ : Haematopoietic growth factors in children with neutropenia. Br J Haematol 2002, 116(1):28-56.

55. Clark OA, Lyman GH, Castro AA, Clark LG, Djulbegovic B: Colony-stimulating factors for chemotherapy-induced febrile neutropenia: a meta-analysis of randomized controlled trials. J Clin Oncol 2005, 23(18):4198-4214.

56. Gruson D, Hilbert G, Vargas F, Valentino R, Chene G, Boiron JM, Reiffers Gbikpi-Benissan G, Cardinaud JP: Impact of colony-stimulating factor therapy on clinical outcome and frequency rate of nosocomial infections in intensive care unit neutropenic patients. Crit Care Med 2000, 28(9):3155-3160.

57. Karlin L, Darmon M, Thiery G, Ciroldi M, de Miranda S, Lefebvre A Schlemmer B, Azoulay E: Respiratory status deterioration during G-CSF-induced neutropenia recovery. Bone Marrow Transplant 2005, 36(3):245-250

58. Stanworth SJ, Massey E, Hyde C, Brunskill S, Lucas G, Navarrete C, Marks DI: Granulocyte transfusions for treating infections in patients with neutropenia or neutrophil dysfunction. Cochrane Database Syst Rev 2005, 3, CD005339.

59. Cherif $\mathrm{H}$, Axdorph U, Kalin M, Bjorkholm M: Clinical experience of granulocyte transfusion in the management of neutropenic patients with haematological malignancies and severe infection. Scand J Infect Dis 2013, 45(2):112-116.

60. Hentrich M, Fehnle K, Ostermann H, Kienast J, Cornely O, Salat C, Ubelacker R, Buchheidt D, Behre G, Hiddemann W, Schiel X: IgMA-enriched immunoglobulin in neutropenic patients with sepsis syndrome and septic shock: a randomized, controlled, multiple-center trial. Crit Care Med 2006, 34(5):1319-1325.

61. Kanamaru A, Tatsumi Y: Microbiological data for patients with febrile neutropenia. Clin Infect Dis 2004, 39(Suppl 1):S7-S10.

62. Irfan $\mathrm{S}$, Idrees F, Mehraj V, Habib F, Adil S, Hasan R: Emergence of Carbapenem resistant Gram negative and vancomycin resistant Gram positive organisms in bacteremic isolates of febrile neutropenic patients: a descriptive study. BMC Infect Dis 2008, 8:80. 
63. Tumbarello M, Sanguinetti M, Montuori E, Trecarichi EM, Posteraro B, Fiori B, Citton R, D'Inzeo T, Fadda G, Cauda R, Spanu T: Predictors of mortality in patients with bloodstream infections caused by extended-spectrumbeta-lactamase-producing Enterobacteriaceae: importance of inadequate initial antimicrobial treatment. Antimicrob Agents Chemother 2007, 51(6):1987-1994

64. Gudiol C, Bodro M, Simonetti A, Tubau F, Gonzalez-Barca E, Cisnal M, Domingo-Domenech E, Jimenez L, Carratala J: Changing aetiology, clinical features, antimicrobial resistance, and outcomes of bloodstream infection in neutropenic cancer patients. Clin Microbiol Infect 2013, 19(5):474-479.

65. Cuzon G, Naas T, Nordmann P: [KPC carbapenemases: what is at stake in clinical microbiology?]. Pathol Biol (Paris) 2010, 58(1):39-45.

66. Chemaly RF, Hanmod SS, Jiang Y, Rathod DB, Mulanovich V, Adachi JA, Rolston KV, Raad II, Hachem RY: Tigecycline use in cancer patients with serious infections: a report on 110 cases from a single institution. Medicine (Baltimore) 2009, 88(4):211-220.

67. Cattaneo C, Quaresmini G, Casari S, Capucci MA, Micheletti M, Borlenghi E, Signorini L, Re A, Carosi G, Rossi G: Recent changes in bacterial epidemiology and the emergence of fluoroquinolone-resistant Escherichia coli among patients with haematological malignancies: results of a prospective study on 823 patients at a single institution. J Antimicrob Chemother 2008, 61(3):721-728.

68. Herrero IA, Issa NC, Patel R: Nosocomial spread of linezolid-resistant, vancomycin-resistant Enterococcus faecium. N Engl J Med 2002, 346(11):867-869.

69. Pfaller MA, Messer SA, Hollis RJ, Jones RN, Diekema DJ: In vitro activities of ravuconazole and voriconazole compared with those of four approved systemic antifungal agents against 6,970 clinical isolates of Candida spp. Antimicrob Agents Chemother 2002, 46(6):1723-1727.

70. Diekema DJ, Messer SA, Hollis RJ, Jones RN, Pfaller MA: Activities of caspofungin, itraconazole, posaconazole, ravuconazole, voriconazole, and amphotericin B against 448 recent clinical isolates of filamentous fungi. J Clin Microbiol 2003, 41(8):3623-3626.

71. Karwa R, Wargo KA: Efungumab: a novel agent in the treatment of invasive candidiasis. Ann Pharmacother 2009, 43(11):1818-1823.

72. Krenova Z, Pavelka Z, Lokaj P, Skotakova J, Kocmanova I, Teyschl O, Kren L, Mudry P, Sterba J: Successful treatment of life-threatening Candida peritonitis in a child with abdominal non-Hodgkin lymphoma using Efungumab and amphotericin B colloid dispersion. J Pediatr Hematol Oncol 2010, 32(2):128-130.

73. Ostrosky-Zeichner L: Combination antifungal therapy: a critical review of the evidence. Clin Microbiol Infect 2008, 14(Suppl 4):65-70.

74. Walsh TJ, Anaissie EJ, Denning DW, Herbrecht R, Kontoyiannis DP, Marr KA, Morrison VA, Segal BH, Steinbach WJ, Stevens DA, van Burik JA, Wingard JR, Patterson TF: Treatment of aspergillosis: clinical practice guidelines of the Infectious Diseases Society of America. Clin Infect Dis 2008, 46(3):327-360.

doi:10.1186/1471-2334-14-512

Cite this article as: Zafrani and Azoulay: How to treat severe infections in critically ill neutropenic patients? BMC Infectious Diseases 2014 14:512.

\section{Submit your next manuscript to BioMed Central and take full advantage of:}

- Convenient online submission

- Thorough peer review

- No space constraints or color figure charges

- Immediate publication on acceptance

- Inclusion in PubMed, CAS, Scopus and Google Scholar

- Research which is freely available for redistribution

Submit your manuscript at www.biomedcentral.com/submit
() Biomed Central 